\title{
Insertion of Salt Stratification when Building Detailed Velocity Models and its Impacts Regarding Uncertainties Analysis for Gross-Rock Volumes Estimation
}

\author{
(1) Petrobras S.A., Rio de Janeiro, RJ, Brazil; \\ (2) Universidade Federal Fluminense, Niterói, RJ, Brazil; \\ (3) Heriot-Watt University, Edinburgh, UK; \\ (4) Emerson Automation Solutions, Rio de Janeiro, RJ, Brazil.
}

Alexandre Maul (1, 2, 3)*; Marco Cetale (2); Cleverson Guizan (2); Patrick Corbett (3); John Underhill (3); Leonardo Teixeira (1, 2); Rodrigo Pontes (1, 2); Lívia Falcão (1, 2); Thiago Yamamoto (1, 2) \& María González (4)

Copyright 2021, SBGf - Sociedade Brasileira de Geofísica

This paper was prepared for presentation during the $17^{\text {th }}$ International Congress of the Brazilian Geophysical Society held in Rio de Janeiro, Brazil, 16-19 August 2021.

Contents of this paper were reviewed by the Technical Committee of the $17^{\text {th }}$ International Congress of the Brazilian Geophysical Society and do not necessarily represent any position of the SBGf, its officers or members. Electronic reproduction or storage of any part of this paper for commercial purposes without the written consent storage of any part of this paper for commercial
of the Brazilian Geophysical Society is prohibited.

\begin{abstract}
The pre-salt reservoirs in the Santos Basin, Brazil, are below a salt section varying from few meters to more than two kilometers thick. As many other salt bodies in the world, this layer is not fully composed of halite. According to earlier publications, the halite content is about $70-90 \%$ in the thicker portions, and something about $50-70 \%$ in the thinner portions. Stratifications of anhydrite and other evaporites are also present. This heterogeneity led to the development of a methodology to include the stratifications in velocity models in order to improve the seismic image of the pre-salt reservoirs. Enhanced seismic images are great examples of the success of the method application. However, despite the great advantages of considering heterogeneous salt velocities, assigning a proper compressional velocity for the different salts stratifications is difficult and uncertain. Here, we want to demonstrate how to build salt velocity models, from the simplest to the most complex approach, and how they affect the seismic imaging, the event positioning in order to add more value to the project.
\end{abstract}

\section{Introduction}

Since the first discoveries in the pre-salt reservoir (Santos Basin, offshore Brazil) in 2005, more than 250 wells were drilled in order to reach the carbonate reservoirs in the Barra Velha and Itapema formations (Maul, 2020). These Aptian-aged formations represent the initial stage of the evaporitic phase within this basin. In order to reach these pre-salt reservoirs, it is necessary to cross the saline evaporitic section - which, in the Santos Basin, receives the name of Ariri Formation, and can range from a few meters to more than two kilometers in thickness.
However, as in many basins around the world, the evaporitic section is not fully composed of halite. In past years, due to the absence of detailed knowledge about the salt composition (or, sometimes, lack of computational power to properly address it, especially in terms of seismic processing), treating this section as homogeneous (with halite properties) was considered acceptable. This assumption delivered quite reasonable results, particularly if we consider that drilling through the salt layer was the exception, rather than the rule. With the discovery of the pre-salt reservoirs, however, this changed and since then, several disciplines have been struggling to better understand and characterize the evaporitic section in the Santos Basin. Greater understanding of the salt layer results in improvements in several activities in the field assessment and development workflow, like illumination studies for seismic acquisition, seismic processing, uncertainty analysis for depth positioning, seismic signal quality, and geomechanical simulation studies, to cite a few.

In this revision study, we present the state of the art in terms of the evaporitic layer characterization, focusing in the Santos Basin and presenting some case studies and the impacts of this characterization regarding the grossrock volumes uncertainties. The methodology was initially developed to characterize the evaporitic section using well data and seismic amplitude data. This idea evolved into using seismic inversion data, considering only the top and base of the evaporitic section to guide the low frequency model. In parallel, facies classification was also incorporated. Later, due to the absence of drilled wells to control the seismic inversion or facies classification in exploration areas, the use of "masks" from seismic attributes and/or pseudo-well information has also provided better results. Our last developments include incorporating more stratigraphy in the low frequency model, by adding some internal horizons in the salt layer - what some authors deem internal salt cycles (Freitas, 2006; Gamboa et al., 2009; Rodriguez et al., 2018; Pontes, 2019, Teixeira et al., 2020). 


\section{Method}

There is plenty of information in the literature describing the difficulty to perform good seismic migration when not considering the heterogeneities of the evaporitic section (Ji et al., 2011), as well as the difficulty to build accurate seismic images near to evaporitic bodies, due to significant lateral velocity variations (Jones and Davison, 2014). Huang et al. (2010) defend the idea to use tomography to update the velocity model, in an attempt to represent the layered evaporites in the Santos Basin. Maul et al. (2015) and Maul (2020) mention the necessity of incorporating existing heterogeneities in the evaporitic section (the so-called stratification) in order to ensure proper image focusing below the evaporitic section, which is crucial both for structural interpretation and for using seismic attributes as drift for distribution of log-derived properties. Although we advocate the inclusion of the stratifications to represent the salt depositional environment, the main message we would like to convey is the necessity of not treating this section as homogeneous.

We summarize the understanding of the level of geology for an evaporitic section in Figure 1, where we present a few ways to build the velocity model for this section. The models increase in complexity, starting with a simple approach or assumption, which considers this section as homogenous (a halite layer) and evolves with the incorporation, in steps of increasing complexity, of more details in the salt later.
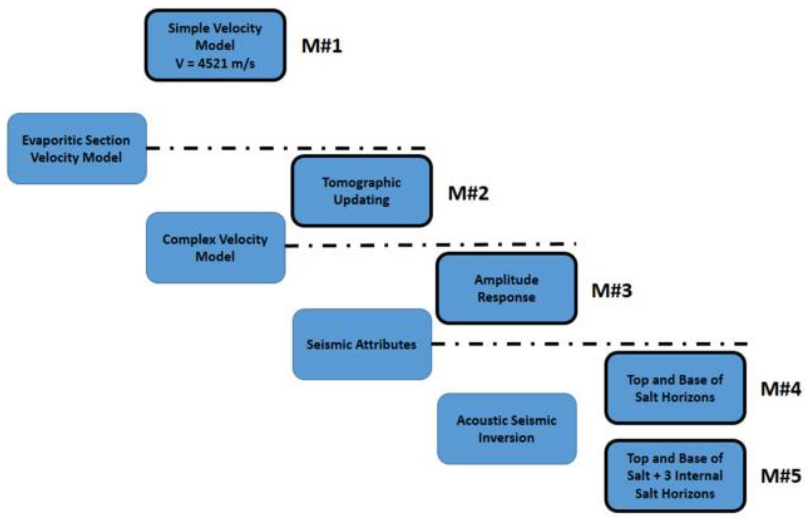

Figure 1 - A simple workflow showing several ways to build velocity models for the evaporitic section, starting from a homogeneous model and evolving many ways of inserting the heterogeneities necessary to improve the quality of the seismic data. Adapted from Maul (2020).

M\#1 considers the salt section as a constant velocity model. M\#2 considers one of standard way in building velocity models for seismic migration, i.e., adopting the inversion tomographic updating process. M\#3, after seismic migration, takes an initial and constant salt velocity model $(4521 \mathrm{~m} / \mathrm{s})$ and applies perturbations in order to increase the velocity according to the seismic attribute response (Falcão, 2017). M\#4 is a step further of the $\mathrm{M \# 3}$, but instead of using the amplitude response to include the intrasalt velocity, it performs model-based seismic inversion using top and base of salt as the boundaries of the model (Yamamoto, 2019). M\#5 takes a step further from $\mathrm{M \# 4}$, adding three more internal horizons to build the salt model using inversion, as well as the top and base of the salt. Those horizons were an attempt at reflecting the $4^{\text {th }}$ order salt precipitation cycles in the Santos Basin (Pontes, 2019).

The compressional velocity distribution is another key factor to consider when building velocity models for the salt section. In the majority of the studied wells, we can see the halite predominates, reaching percentages of about $70-90 \%$ in the thicker portions. However, this percentage decreases to something about $50-70 \%$ in the thinner portions. Maul et al. (2019) present a table (Table 1) containing 182 wells split by fields, summarizing the percentage for each studied fields, grouping the evaporites in three categories: LVS (Low Velocity Salts) mainly composed by tachyhydrite, carnallite and sylvite; the halite by itself (the background evaporite); and HVS (High Velocity Salts), composed by anhydrite and gypsum.

Table 1 - Salt proportions and compressional velocity $(\mathrm{m} / \mathrm{s})$ for nine fields (182 wells) inside the Santos Basin. LVS: Low Velocity Salts; HVS: High Velocity Salts; ACV: Average Compressional Velocity; WCV: Weighted Compressional Velocity; TNW: Total Number of Wells; Compressional Velocity (M/S); AVG: Average. Adapted from Maul et al. (2019).

\begin{tabular}{|c|c|c|c|c|c|c|c|c|}
\hline Field & \#Wells & \% LVS & LVS ACV & \% Halite & HaliteACV & \% HVS & HVS ACV & WCV \\
\hline $\mathbf{1}$ & 20 & 8 & $4.018,56$ & 83 & $4.480,88$ & 8 & $5.210,27$ & $4.462,56$ \\
\hline $\mathbf{2}$ & 29 & 9 & $4.218,47$ & 82 & $4.563,69$ & 9 & $4.975,84$ & $4.567,53$ \\
\hline $\mathbf{3}$ & 17 & 12 & $4.054,42$ & 77 & $4.498,25$ & 12 & $4.989,92$ & $4.505,66$ \\
\hline $\mathbf{4}$ & 3 & 13 & $3.971,00$ & 71 & $4.507,09$ & 16 & $4.927,59$ & $4.505,04$ \\
\hline $\mathbf{5}$ & 5 & 3 & $4.167,00$ & 84 & $4.538,00$ & 13 & $5.123,33$ & $4.576,00$ \\
\hline $\mathbf{6}$ & 7 & 3 & $4.264,19$ & 80 & $4.509,87$ & 17 & $5.061,36$ & $4.596,05$ \\
\hline $\mathbf{7}$ & 72 & 8 & $4.122,33$ & 81 & $4.526,47$ & 11 & $5.105,84$ & $4.560,03$ \\
\hline $\mathbf{8}$ & 25 & 4 & $4.182,53$ & 88 & $4.533,59$ & 8 & $5.003,35$ & $4.547,16$ \\
\hline $\mathbf{9}$ & 4 & 6 & $4.055,63$ & 81 & $4.486,58$ & 13 & $5.077,49$ & $4.535,67$ \\
\hline TNW & 182 & & & & & & & \\
\hline AVG & & 7 & $4.117,13$ & 81 & $4.516,05$ & 12 & $5.052,78$ & $4.539,52$ \\
\hline
\end{tabular}

Complementing this previous approach, Meneguim et al. (2015) developed a way to compute the gross-rock volumes (GRV) above a reference level for different evaporitic section scenarios, ranging from homogenous (pure halite) to heterogeneous layers. Paes et al. (2019) adapted this solution by adding the uncertainty of seismic resolution to the calculation of GVR.

There is plenty of literature discussing the internal layering of the evaporitic section in the Santos Basin. Gamboa et al. (2009) mention the existence of four major evaporitic depositional cycles observed in seismic data and well information, corresponding to stratigraphic events of $3^{\text {rd }}$ and $4^{\text {th }}$ orders. They use the idea defended by Freitas (2006), who mapped these cycles using well information from dozens of minor cycles $\left(4^{\text {th }}, 5^{\text {th }}\right.$ and $6^{\text {th }}$ orders). Later, Jackson et al. (2015) proposed a classification that presents a correspondence with the one presented by Gamboa et al. (2009). Pontes (2019) has shown the advantages of including the evaporitic cycles of deposition for any seismic process. Fiduk and Rowan (2012) described a similar classification for these four main units, with some differences on how the basal units are split.

Regarding the salt cycles inclusion prior to the seismic inversion, Pontes (2019) has also tested the same kind of 
calculation. The different methodologies delivered similar results, indicating that the GRV can vary from $2 \%$ to $6 \%$ when considering or not the salt stratification. This last author also measured the differences between the forecasted and detected pre-salt reservoirs, considering homogeneous and heterogeneous models, as well as the inclusion of salt cycles to control the velocity model, concluding that the most accurate model is the one having the salt cycles for the inversion process.

The described concepts have been applied in many real projects. Maul et al. (2018) present a compendium of applications based on the methodology of stratification of the evaporitic section, covering several E\&P areas. We highlight a case study presented by Fonseca et al. (2018) where the authors compare seismic sections migrated with a velocity model with and without the salt model. The salt stratification leads to the enhancements in image focusing/sharpening, characterization of geological features, attenuation of pull-up and push-downs features, and cost reduction due to fewer number of iterations needed to update the velocity model, using tomographic inversion prior to migration. Figure 2 exemplifies these results.

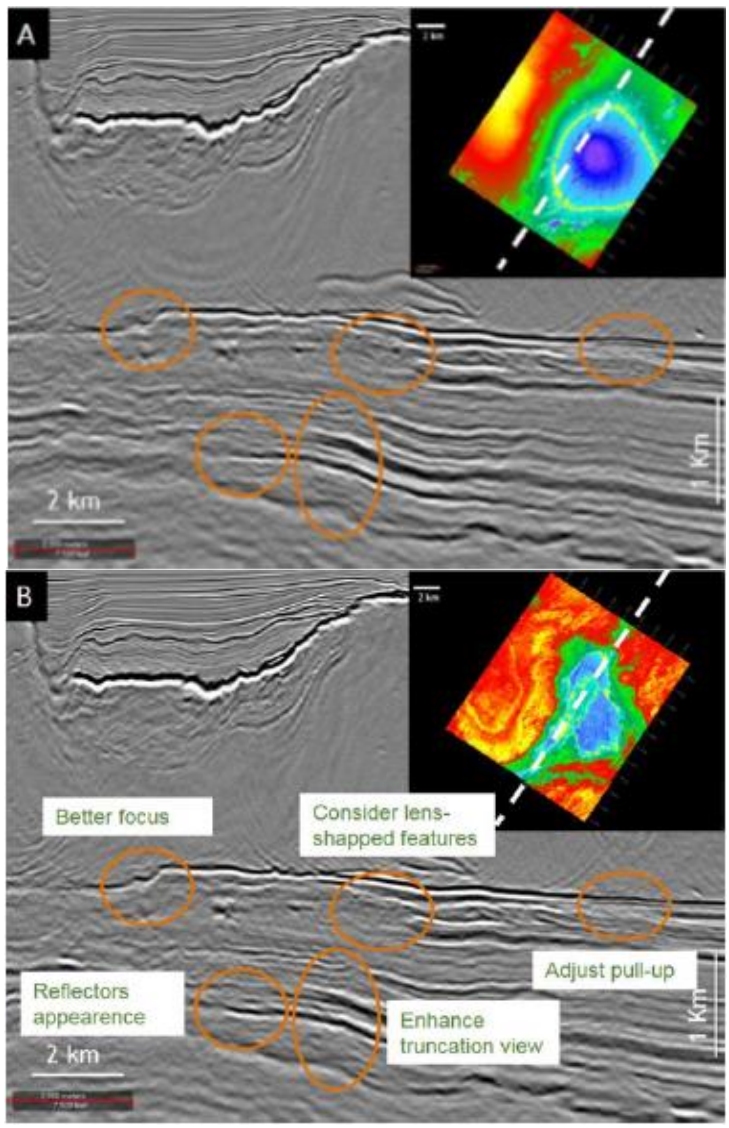

Figure 2 - Comparison of Kirchhoff seismic migrations without $(A)$ and with $(B)$ the salt stratigraphic insertion in the evaporitic section. The seismic image presented in $(B)$ is much more accurate than the one presented in $(A)$. The map considering the salt stratification $(B)$ is more heterogeneous than the smoothed one presented in the standard model (A). Figure used under permission of the authors (Fonseca et al., 2018).

\section{Results}

Using the information from figure 2 and taking into account the interval velocity variability measured in the studied wells it is possible to generate PDF distributions for each group and compute its average values. In this case it was just computed the arithmetic average. We investigated in detail the influence of the interval velocity on the depth positioning and GRV estimations. Using the sonic log from 14 wells, we calculated the compressionalaverage velocity for each of the three salt groups (LVS, Halite and HVS) and the mineral assembly. That calculation estimates the standard deviation of each mineral group reflecting the dispersion of interval velocities to the averages (Figure 3 ).

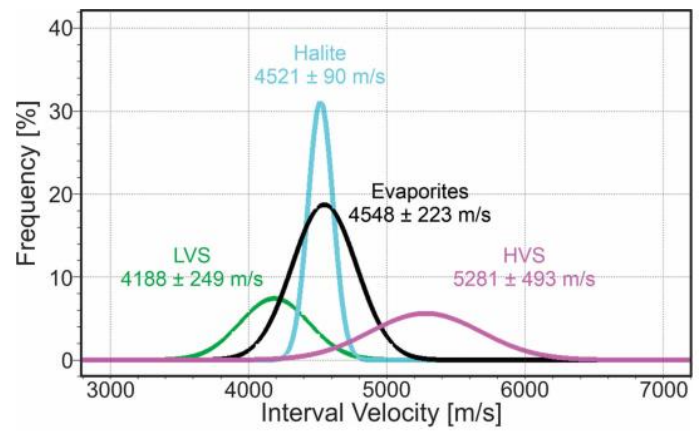

Figure 3 - PDF of mineral compressional velocity variation obtained from the well logs considering a sample of 10 wells, among the 182 ones summarized in figure 2. Adapted from Maul et al. (2019).

We emphasize some assumptions: 1) Halite presents the smaller velocity value dispersion and, since it represents about $80 \%$ of occurrence, this lithology controls the interval velocity behavior in the salt section. 2) Salt mixtures (grouped as evaporites) can explain the high degree of dispersion, but still have similar interval velocity value as pure halite. The interval velocity for the evaporites $(4548 \mathrm{~m} / \mathrm{s})$ is very similar to the halite $(4521$ $\mathrm{m} / \mathrm{s}$ ) due to the high percentage of halite (about $80 \%$ ). However, it imposes a level of dispersion $(+/-223 \mathrm{~m} / \mathrm{s})$ that is about 2.5 times the halite dispersion $(+/-90 \mathrm{~m} / \mathrm{s})$. The mixture occurs due to the intense salt movement present in the basin; and 3) Both the LVS and HVS present larger dispersions, chiefly because they comprise different minerals with specific velocities. The small percentage of occurrence - in average $7 \%$ for LVS and $12 \%$ for the HVS - affects significantly the dispersions in these mineral assemblies than it affects the more abundant halite.

We compared the depths of the seismic horizon and the well markers of the base of the salt for each well before performing the calibration with the well information. We present the depth difference of the base of the salt reflector in each model and the base of the salt well marker (Table 2). The average difference (AVG D) reflects the addition of positive and negative difference values divided by the total number of wells (14). We calculated the average of the difference modulus (AVG $|D|)$ avoiding the cancelation of positive and negative values, otherwise expressing the real differences of the velocity models. 
Table 2 - Differences, in meters, between the well marker of the base of salt and the depth conversion of the base of salt seismic horizon taking the 5 models we previously described.

\begin{tabular}{|c|r|r|r|r|r|}
\cline { 2 - 7 } \multicolumn{1}{c|}{} & \multicolumn{5}{c|}{ Differences from well marker of the base of salt } \\
\hline Well & M\#1 & \multicolumn{1}{c|}{ M\#2 } & \multicolumn{1}{c|}{ M\#3 } & \multicolumn{1}{c|}{ M\#4 } & \multicolumn{1}{c|}{ M\#5 } \\
\hline A & -51.75 & -46.18 & -21.94 & -12.86 & -5.91 \\
\hline B & -15.30 & -33.38 & -17.22 & -12.44 & -13.36 \\
\hline C & -19.83 & -6.15 & -9.29 & -5.16 & -1.54 \\
\hline D & -18.18 & -34.22 & -16.29 & -6.24 & -8.46 \\
\hline E & 13.51 & 9.62 & 8.80 & 8.06 & 6.54 \\
\hline F & -22.33 & -20.05 & -24.45 & -18.75 & -9.91 \\
\hline G & -6.39 & -10.08 & -1.54 & 4.47 & 0.31 \\
\hline H & -13.54 & -9.03 & -9.39 & -9.94 & -7.66 \\
\hline I & 13.72 & 15.88 & 5.45 & 4.12 & -0.98 \\
\hline J & 13.70 & 6.23 & 7.81 & 7.33 & -6.16 \\
\hline K & -12.59 & -3.93 & -8.26 & -7.86 & -5.72 \\
\hline L & -21.76 & -19.78 & -19.09 & -15.30 & -11.82 \\
\hline M & -20.72 & -10.18 & -8.72 & -4.67 & -4.38 \\
\hline N & 22.36 & 14.81 & 6.53 & 9.74 & 5.83 \\
\hline AVG D & -9.93 & -10.46 & -7.69 & -4.25 & -4.52 \\
\hline AVG|DI & $\mathbf{1 8 . 2 6}$ & $\mathbf{1 7 . 1 1}$ & $\mathbf{1 1 . 7 7}$ & $\mathbf{9 . 0 7}$ & $\mathbf{6 . 3 3}$ \\
\hline
\end{tabular}

Adapted from Maul (2020).

We performed the calibration of the five models with the well velocities, adopting the kriging with external drift (KED) algorithm. Firstly, we converted the interval velocity to the average velocity and used it as the drift information. All the aspects, such as the searching and analysis parameters, spherical and isotropic variogram considering $10 \%$ of the samples, average distance among wells as radius of influence are the same for the models. We did not change the velocities of the pre-salt and the post-salt sections.

After the calibration of the five models, we converted the time-domain horizon of the base of the salt and computed the Gross-Rock Volume (GRV) having the oil-water (OW) contact as reference in order to emphasize quantify the main volumetric variations of the models (Figure 4).

Effective (above the OW contact) GRV variations $(e+10) \rightarrow \mathrm{m}^{3}$

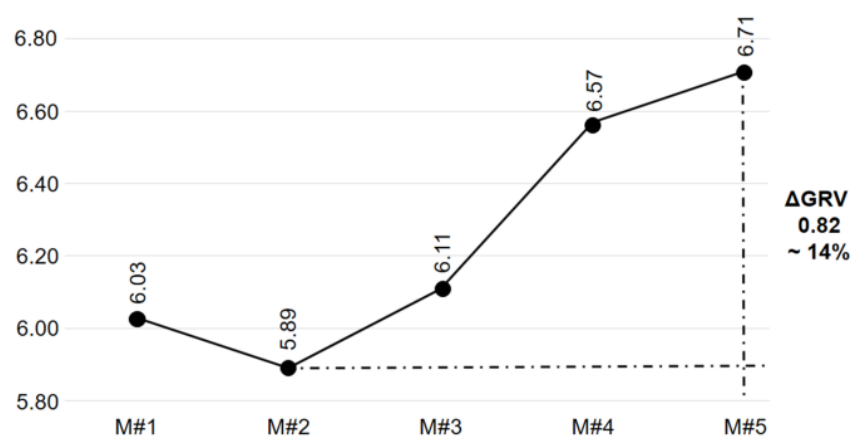

Figure 4 - GRV (in million cubic meters) calculated for the five models (M\#1, M\#2, M\#3, M\#4 and M\#5). An estimated difference of $14 \%$ in GRV is observed between M\#2 (the reference model) and model M\#5 (seismic inversion considering the intrasalt cycle). Adapted from Maul (2020).
Another important aspect to consider besides the GRV variation is where the main differences are observed. Thus, we present the maps of the depth surfaces representing all the models used intercepted by the oil \& water contact (Figure 5).
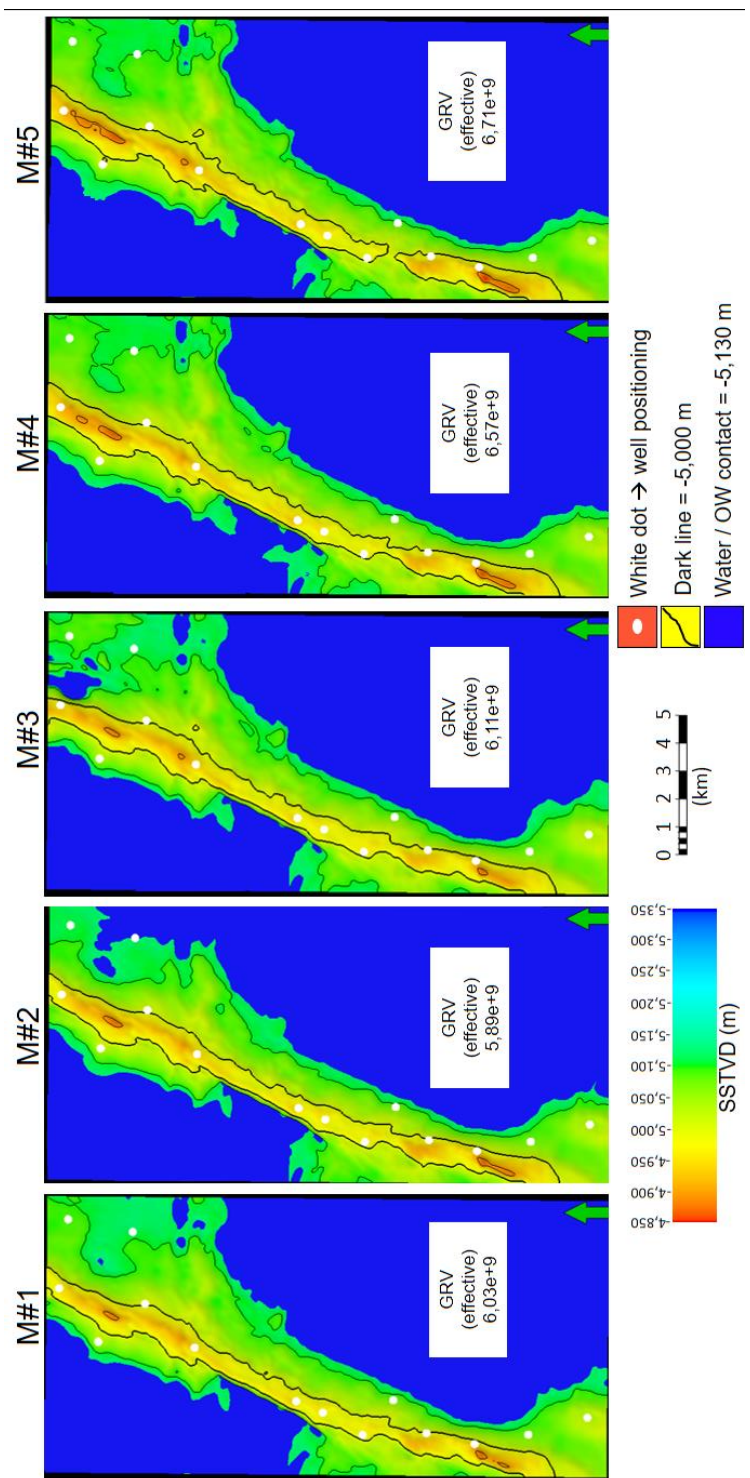

Figure 5 - Areal representation of M\#1, M\#2, M\#3, M\#4 and M\#5 intercepted by the oil \& water contact. Adapted from Maul (2020).

\section{Discussion}

During the calibration process, we measured the final depths of the halite per well and at the positive time peak from the seismic data at the well locations. Having this information, we calculated the average velocity at well locations for all the five models. The basal anhydrite average thickness nearly 14 meters (Maul, 2020) and it is below the seismic resolution, here varying from 50 to 60 meters in these geological conditions. Therefore, it is reasonable to consider it when performing uncertainty 
analysis, especially accounting the volumetric hydrocarbon calculation.

The average interval velocities taken from the sonic logs for different salt assemblies are respectively: $4188 \mathrm{~m} / \mathrm{s}$ for LVS; $4521 \mathrm{~m} / \mathrm{s}$ for halite; $5281 \mathrm{~m} / \mathrm{s}$ for HVS; and 4548 $\mathrm{m} / \mathrm{s}$ for all the evaporates as presented in figure 3 . Using the drill cutting samples as reference, we included the pseudo-velocities information along sonic-log gaps, and determined the average interval velocity of $4585 \mathrm{~m} / \mathrm{s}$ for the 14 wells. This analysis reinforces the fact that we must deal with the velocity variations inside the salt section in order to get reliable models and its related uncertainties.

The tomographic velocity model updating (M\#2) is still one of the standard models for the oil \& gas industry, which delivers good seismic images, however it does not present a clear match with the internal stratigraphy in the saline evaporitic section. As mentioned by Guo and Fagin (2002), the tomographic process is a mathematical approach searching for the gather alignments and is a powerful tool, although not necessarily honoring the existing geology. Differently, the models M\#3 (amplitude response) and $\mathrm{M} \# 4$ (model-based seismic inversion, in that case only considering the horizons of the top and base of the salt) gave us good results also related to the internal features. However, when we quantify the error, M\#5 delivers the best results. This model, besides using the top and base of salt during the seismic inversion, also considers three other internal horizons reflecting $4^{\text {th }}$ order cycles of evaporite deposition.

It is important to notice the modulus consideration when evaluating the model's error is a key factor once we have no chance to reduce the errors by computing positive and negative values to calculate the averages. The sum of depth positioning modular differences from the well markers and unconstrained depth-converted horizons of the base of the salt shows a decrease from $17.11 \mathrm{~m}$ to $6.33 \mathrm{~m}$ for $\mathrm{M \# 5}$, which suggests that this is the most precise model as we see consulting table 2 .

Even with the best applied model (M\#5) the calibration process is essential in order to honor the well information. Using kriging with external drift (KED) we can estimate how the GRV varies above the OW. Among the five models, the larger difference is between M\#2 and M\#5, showing that the volumetric uncertainty is captured when analyzing the results delivered from these models. Considering the oil-saturated GRV, we quantified a positive variation of $14 \%$ from $M \# 2$ to $M \# 5$, which can accommodate an order of $3 \%$ of oil volume variation, with an average total $20 \%$ reservoir porosity.

Infill well drilling campaigns need confident information in order to map remaining oil accumulations. Observing the maps presented in figure 5 , besides to consider the GRV variation we can note that $\mathrm{M \# 5}$, at the Northern half portion could represent an important area to locate new wells due to the extension of the area above the oil \& water contact. More than this we can identify portions structurally higher than the other maps. Saller et al. (2016) defend the best porosities of the pre-salt carbonate reservoir are locate in the higher portions of the structure. Latter, Faria et al. (2017) dealing with the same production field we work in this paper confirm this same behavior regarding porosity in relation with the higher portions of the field.

\section{Conclusions}

The velocity model of saline evaporitic section in the Santos Basin represents over than $50 \%$ of the entire velocity model. Thus, this portion has a strong influence on the establishment for the position of the reservoir structures in the pre-salt section. Therefore, lacking its proper representation, especially the absence of geological complexity, imposes a huge risk for the development of pre-salt fields. In this work, we presented and discussed about methodologies to build velocity models for the salt section considering the heterogeneities observed in the amplitude seismic response and well logs.

Even if the predominance of halite is more than $80 \%$ in average, the stratifications inside the salt section suggest the presence of other types of evaporitic minerals. The identification, separation and quantification of LVS and HVS proved to be a powerful tool to build reliable velocity models for several applications in the oil \& gas industry. Among them, it is the GRV quantification above OW contact, as demonstrated in this work.

After testing five interval velocity models for the salt section, we confirmed that the salt-cycle inversion approach (M\#5), inserting salt heterogeneities related to cycles of salt precipitation, delivers the more accurate depth prediction, decrease the sum of absolute imprecision from the order of $20 \mathrm{~m}$ to something about 5 $\mathrm{m}$ in average.

We performed the well calibration and quantified the oilsaturated GRV for each one. That information allowed us to calculate the difference among the models. In our case, the previous base scenario following the tomographic update (M\#2) delivers the smaller volume among the five. The salt-cycle inversion approach (M\#5) delivers the larger GVR volumes above the OW contact, consequently increasing oil volume estimations adding a valuable contribution for infill drilling campaigns.

As the thick salt section in the Santos Basin in not homogenous, the uncertainties related to depth positioning when assuming less geological scenarios for the salt section in terms of velocity can mislead project decisions. The approach to build the velocity models is well documented, and feasible, not overtaking any project time-line.

\section{Acknowledgments}

The authors would like express their gratitude to PETROBRAS for giving all the needed support and time to develop this research, as well as for allowing this publication, and to ANP to provide the data used for the tests. 


\section{References}

Falcão, L. 2017. O Sal Estratificado e sua Importância na Modelagem de Velocidades para Fins de Migração Sísmica. Master's Dissertation. UFF. Niterói, RJ, Brazil.

Faria, D.L., Reis, A.T. \& Souza Jr., O.G. 2017. Threedimensional stratigraphic sedimentological forward modeling of an Aptian carbonate reservoir deposited during the sag stage in the Santos Basin, Brazil. MPG, 88, 676-695. doi: 10.1016/j.marpetgeo.2017.09.013.

Freitas, J.T.R. 2006. Ciclos Deposionais Evaporíticos da Bacia de Santos, uma Análise Cicloestratigráfica à partir de Dados de 2 Poços e de Traços de Sísmica. Master's Dissertation. UFRGS. Porto Alegre, RS, Brazil.

Fiduk, J.C. \& Rowan, M.G. 2012. Analysis of Folding and Deformation within Layered Evaporites in Blocks BM-S-8 \& BM-S-9, Santos Basin, Brazil. In: Alsop, G.l., Archer, S.G., Hartley, A.J., Grant, N.T. \& Hodgkinson, R. (Eds.). Salt Tectonics, Sediments and Prospectivity: Geological Society of London Special Publication 363, p. 471-487. doi: 10.1144/SP363.22.

Fonseca J., Teixeira L., Maul A., Barros P., Boechat J. \& González M. 2018. Modelling Geological Layers into new Velocity Models for Seismic Migration Process: A Brazilian Pre-Salt Case. First EAGE/PESGB Workshop on Velocities. London, UK. doi: 10.3997/22144609.201800010.

Gamboa, L.A.P., Machado, M.A.P., Silveira, D.P., Freitas, J.T.R., Silva, S.R.P., Mohriak, W., Szatmari, P. \& Anjos, S. 2009. Evaporitos Estratificados no Atlântico Sul: Interpretação Sísmica e Controle Tectono-Estratigráfico na Bacia de Santos. In: Mohriak, W., Szatmari, P. \& Anjos, S. (Eds.). Sal: Geologia e Tectônica. São Paulo, p. 340-359. Beca Edições.

Guo, N. and Fagin, S. 2002. Becoming effective velocity model builders and depth imagers, Part 2 - the basics of velocity-model building, examples and discussions. The Leading Edge, 1210-1216.

Huang, Y., Lin, D., Bai, B., Roby, S. \& Ricardez, C. 2010. Challenges in Pre-Salt Depth Imaging of the Deepwater Santos Basin, Brazil. The Leading Edge, 29(7): 820-825. doi: 10.1190/1.3462785.

Jackson, C.A.L., Jackson, M.P.A., Hudec, M.R. \& Rodriguez, C.R. 2015. Enigmatic Structures within Salt Walls of the Santos Basin - Part 1: Geometry and Kinematics from 3D Seismic Reflection and Well Data. Journal of Structural Geology, 75: 135-162. doi: 10.1016/j.jsg.2015.01.010.

Ji, S., Huang, T., Fu, K. \& Li, Z. 2011. Dirty Salt Velocity Inversion: The Road to a Clearer Subsalt Image. Geophysics, 76(5): WB169-W174. doi: 10.1190/GEO2010-0392.1.

Jones, I. F. \& Davison I. 2014. Seismic Imaging in and around Salt Bodies. Interpretation, Vol. 2, No.4, SL1SL20. doi: 10.1190/INT-2014-0033.1.
Meneguim, T., Mendes, S., Maul, A., Falcão, L., González, M. \& González, G. 2015. Combining seismic facies analysis and well information to guide new interval velocity models for a pre-salt study, Santos Basin, Brazil. $14^{\text {th }}$ International Congress of the Brazilian Geophysical Society, Rio de Janeiro, RJ, Brazil. doi: 10.1190/sbgf2015-271.

Maul, A. 2020. Caracterização Sísmica da Seção Evaporítica Salina e suas Aplicações nos Projetos de Exploração, Desenvolvimento e Produção de Hidrocarbonetos. Doctor's Thesis. UFF. Niterói, RJ, Brazil.

Maul, A., Cetale, M. \& Guizan, C. 2018. Few Considerations, Warnings and Benefits for the E\&P Industry when Incorporating Stratifications inside Salt Sections. Brazilian Journal of Geophysics, 36(4): 461477. doi: 10.22564/rbgf.v36i4.1981.

Maul, A., Jardim, F., Falcão, L. \& González, G. 2015. Observing Amplitude Uncertainties for a Pre-salt Reservoir using Illumination Study (Hit-maps). $77^{\text {th }}$ EAGE Conference and Exhibition. Expanded Abstracts. Madrid, Spain. doi: 10.3997/2214-4609.201412921.

Paes, M., Pereira, C.E., Pinto, V., Maul, A, González, M., Meneguim, T., González, G. Meyer, R. \& Furland, S. 2019. Brazilian Pre-Salt Gross-Rock Volume Uncertainties: Integration between Velocity Model and Seismic Resolution. 81 $1^{\text {st }}$ EAGE Conference and Exhibition. Expanded Abstracts. London, United Kingdom. doi: 10.3997/2214-4609.201901460.

Pontes, R. 2019. Seismic Characterization of Internal Salt Cycles: a Case Study in the Santos Basin, Brazil. Master's Dissertation. UFF. Niterói, RJ, Brazil.

Rodriguez, C.R., Jackson, C.A.-L., Rotevatn, A., Bell, R.E. \& Francis, M. 2018. Dual Tectonic-Climatic Controls on Salt Giant Deposition in the Santos Basin, Offshore Brazil: Geosphere 14(1): 1-28. doi: 10.1130/GES01434.1.

Saller, A., Rushton, S., Buambua, L., Inman, K., McNeil, R. \& Dickson, J.T., 2016. Presalt stratigraphy and depositional systems in the Kwanza Basin, offshore Angola. AAPG Bull. 100 (7), 1135e1164. doi: 10.1306/02111615216.

Teixeira, L., Lupinacci, W. and Maul, A. 2020. Quantitative and Stratigraphic Seismic Interpretation of the Evaporite Sequence in the Santos Basin. Marine and Petroleum Geology (122): 1-17. doi: 10.1016/j.marpetgeo.2020.104690.

Yamamoto, T. 2019. Uma Metodologia para a Caracterização da Formação Ariri utilizando dados de Poços e Inversão Sísmica. Master's Dissertation. UFF. Niterói, RJ, Brazil. 